\title{
Paradigm shift: the Copernican revolution in diverticular disease
}

\author{
Angelo Zullo , Luigi Gattab, Roberto Vassalloc, Vincenzo De Francesco d, Raffaele Mantae, Fabio Monicaf, \\ Giulia Fiorini ${ }^{g}$, Dino Vaira ${ }^{g}$
}

Nuovo Regina Margherita Hospital, Rome; Versilia Hospital, Lido di Camaiore; Buccheri la Ferla, Fatebenefratelli Hospital, Palermo; University of Foggia; Generale Hospital, Perugia; Academic Hospital Cattinara, Trieste; S. Orsola Hospital, University of Bologna, Italy

\begin{abstract}
Diverticular disease (DD) is an umbrella definition that includes different clinical conditions ranging from diverticulosis to severe and potentially life-threatening complications. In the last decade, new concepts regarding pathogenetic alterations have been developed, while the diagnostic, clinical and therapeutic approaches to the management of DD patients have changed. The protective role of dietary factors (i.e., fiber) has been questioned, whilst some drugs widely used in clinical practice have been found to have a deleterious effect. The use of antibiotics in all patients with acute uncomplicated diverticulitis was reconsidered, as well as the need for a surgical approach in these patients. Conflicting recommendations in different guidelines were proposed for the treatment of symptomatic uncomplicated DD. An endoscopic classification of DD was introduced, and a "curative" endoscopic approach has been pioneered. Based on these observations, which together amount to a kind of "Copernican revolution" in the management of DD patients, we performed a comprehensive and critical reappraisal of the proposed modifications, aiming to discriminate between certainties and doubts on this issue.
\end{abstract}

Keywords Diverticular disease, pathogenesis, diagnosis, complications

Ann Gastroenterol 2019; 32 (5): 1-13

\section{Introduction}

Diverticular disease (DD) is an umbrella definition that includes different clinical conditions ranging from diverticulosis-the presence of colonic diverticula without symptoms or signs-to severe and potentially life-threatening complications, such as stercoraceous peritonitis due to overt diverticular perforation [1]. Although only a minority of

${ }^{\mathrm{a}}$ Gastroenterology and Digestive Endoscopy, Nuovo Regina Margherita Hospital, Rome (Angelo Zullo); ${ }^{\mathrm{b}}$ Gastroenterology and Endoscopy Unit, Versilia Hospital, Lido di Camaiore (Luigi Gatta); ' Gastroenterology and Digestive Endoscopy; "Buccheri la Ferla, Fatebenefratelli", Hospital, Palermo (Roberto Vassallo); 'Section of Gastroenterology, Department of Medical Sciences, University of Foggia (Vincenzo De Francesco); ${ }^{\mathrm{e}}$ Gastroenterology and Digestive Endoscopy, "Generale" Hospital, Perugia (Raffaele Manta); ${ }^{\mathrm{f} G a s t r o e n t e r o l o g y}$ and Digestive Endoscopy, Academic Hospital Cattinara, Trieste (Fabio Monica); ${ }^{\mathrm{g} D e p a r t m e n t}$ of Medical and Surgical Sciences, S. Orsola Hospital, University of Bologna, Bologna (Giulia Fiorini, Dino Vaira), Italy

Conflict of Interest: None

Correspondence to: Dr. Angelo Zullo, Gastroenterologia ed Endoscopia Digestiva, Ospedale Nuovo Regina Margherita, Via Emilio Morosini, 00153 Rome, Italy, e-mail: angelozullo66@yahoo.it

Received 5 May 2019; accepted 26 June 2019; published online 2 August 2019

DOI: https://doi.org/10.20524/aog.2019.0410
DD patients develop a clinical condition requiring therapy, hospital admission, or surgical intervention, the wide diffusion of DD in the general population-particularly in Western countries-results in a very high consumption of healthcare resources [2]. In the last 2 decades, several changes have occurred in diagnostic procedures, therapeutic interventions and patient management, so that the clinical scenario of DD has indisputably changed [3]. In the past, medical attention was mainly captured by the potential complications of the disease. Indeed, when suspected of having diverticulitis, patients were commonly admitted to hospital, received systemic antibiotics, and frequently underwent a surgical approach-not only in the acute phase, but also in an elective setting when the acute episode resolved. However, recent medical and surgical data have cast doubt on this policy and a more conservative approach, with a case-by-case strategy, has been suggested [4]. An increasing number of DD patients are also receiving medical care, either for treatment of heterogeneous abdominal symptoms, putatively attributed to the presence of diverticula, or for preventing symptoms and/or complications in asymptomatic DD subjects [5]. Moreover, novel entities emerged (or were renewed), such as symptomatic uncomplicated DD (SUDD) or segmental colitis associated with diverticula (SCAD), widening the spectrum of DD manifestations [6]. Likewise, an intriguing role of DD in increasing the risk of colon adenomas and cancer has also been proposed, although the data are still controversial [7]. In addition, knowledge of the role of different 
lifestyle factors in DD has increased, and the value of certain protective factors, such as dietary fiber intake, has recently been questioned [8], while a potential role has emerged for novel aggressive factors in causing DD complications [6]. Finally, an innovative endoscopic approach for diverticula closure has recently been proposed as a novel treatment [9]. Based on these observations, which overall amount to a kind of "Copernican revolution" in the management of DD patients, we believe it is worth performing a critical reappraisal of the proposed modifications, aiming to discriminate between certainties and doubts on this issue.

\section{Epidemiology}

DD was classically considered a condition affecting elderly people in developed Western countries, where it has a prevalence of $70 \%$ in those aged $>70$ years [1]. Indeed, DD prevalence constantly increases starting from 50 years of age. However, the widespread use of colonoscopy in recent decades, mainly for colorectal screening purposes, has also provided novel information on DD in asymptomatic subjects. A recent Italian study of 970 consecutive individuals aged 50-75 years with a positive fecal immunological test, who participated in a colorectal cancer (CRC) screening program and underwent high-quality colonoscopy, found diverticulosis in $36.5 \%$ of subjects [7]. Likewise, $41 \%$ of subjects who underwent screening colonoscopy in the USA had colonic diverticula [10]. Other studies showed that $5-10 \%$ of DD subjects are aged less than 40 years [11]. Moreover, some evidence suggests that diverticulitis in young patients-not uncommonly the clinical onset of DD_-generally has a more aggressive course and frequently requires a surgical approach [12]. In addition, some studies found a large (76-81\%) prevalence of males in diverticulitis patients aged $<40-50$ years compared to those aged $>40$ years $(49 \%)[13,14]$. Data from the USA reported a $26 \%$ increase in admissions for acute diverticulitis, with the greatest increase in those aged 15-44 and 45-64 years [15]. Therefore, when the physician is faced with an acute abdomen in a young patient, particularly a male patient, DD-associated peritonitis should be considered among the potential causes. Nevertheless, some recent data has called into question the poorer clinical course of diverticulitis in young as opposed to more elderly patients [16]; hence, further studies are needed.

Although first described in 1912, right-sided DD has been fully characterized in more recent years. It emerged that a difference does exist between the Caucasian and Asian DD patterns. Left-sided, acquired pseudo-diverticula, whose number tends to increase with age, prone to left-side diverticulitis, are the typical feature in Western subjects [17]. In contrast, in Eastern peoples, true diverticula are right-side, probably dysontogenetic, generally appear in young age, are frequently few or unique, and are inclined to either right-side diverticulitis or diverticular bleeding [17] (Fig. 1). However, more recent observations suggest that left-sided DD is also increasing in Asian subjects, most likely as a result of diet modifications in Eastern countries [18]. Likewise, populationbased studies showed that the difference in the DD pattern in immigrant Asians tended to decrease over time, as the number of years of settlement in the Western country increased [19]. The main epidemiological data are provided in Table 1.

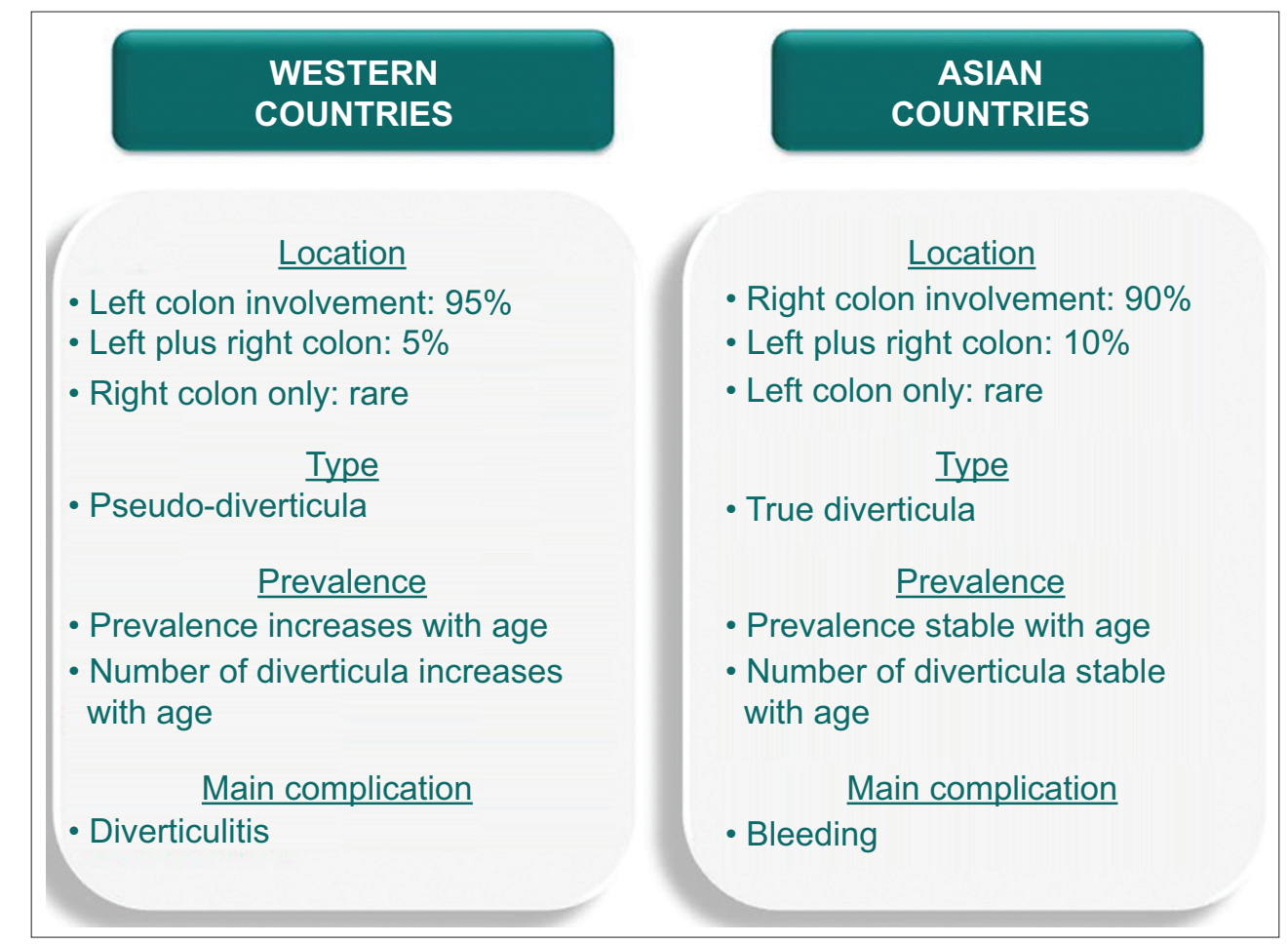

Figure 1 Different characteristics between western and Asian diverticular disease 
Table 1 Epidemiological data

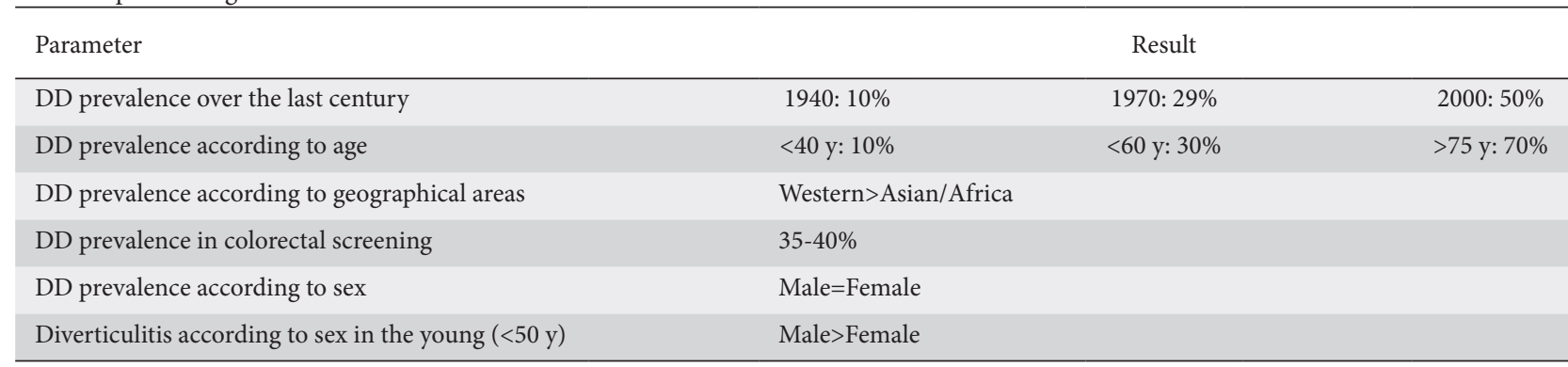

$\overline{D D}$, diverticular disease

\section{Alterations in the colon wall}

Different structural and functional alterations have been described in the colon wall with diverticula, involving all the parietal layers, from mucosa to muscular tunica. The potential role of minimal inflammatory infiltrate in DD mucosa was firstly proposed in 2008 [20]. An increased number of lymphocytes, but not neutrophils [20,21], has been reported in some studies, creating the so-called "subclinical inflammation" [22]. In one study, the mean content of lymphocytes (10 colonic fields with high power field) was 4.1 in controls, 5.9 in asymptomatic DD and 7.3 in symptomatic DD patients [20]. Using a semiquantitative grading from 0 (normal) to 4 (diffuse presence of lymphocytes), the median grade was 1 in DD and 0.5 in controls [23]. Although statistically significant, the difference among groups in these studies does not seem so impressive. Moreover, the content of different inflammatory cytokines and molecules involved in mucosal repair (tumor necrosis factor [TNF]- $\alpha$, syndecan, basic fibroblast growth factor, etc.) has been reported to be increased in DD compared to controls [21]. However, other studies failed to confirm these findings. Using flow cytometric evaluation, lymphocyte percentage and composition (CD4+, CD8+/CD103+, CD25+, and CD62L+) in the sigmoid mucosa did not differ between DD and controls [24]. Moreover, a fine study with biopsies specifically taken around the diverticular, failed to find a difference in interleukin [IL]2, IL4, IL5, IL8, IL10, IL12p70, IL13, interferon- $\gamma$, TNF- $\alpha$, transforming growth factor- $\beta$, and caspase- 9 content between DD and matched controls [25]. Likewise, a recent study found a similar content of lymphocytes, mast cells, IL10, and TNF- $\alpha$ in the colonic mucosa of DD and controls, and a reduced expression of IL6 was even detected in DD [26]. Finally, a recent case-control study involving 254 subjects found no association between DD and either histological or serological (C-reactive protein [CRP]) inflammatory markers, or between these markers and diarrhea or abdominal pain [27]. Consequently, the proposed role of minimal inflammation of the colonic mucosa in generating abdominal symptoms in DD patients remains to be proven [22,26]. For instance, the density of overall immune cells in colon mucosa decreased $(30.66 \pm 1.07$ vs. 25.25 $\pm 0.96 ; \mathrm{P}=0.008$ ) in patients with irritable bowel syndrome (IBS) following mesalazine therapy, but abdominal pain and bloating did not significantly improve [28].

Alterations in both the amount and the composition of collagen in the extracellular matrix of colon wall with diverticula have been documented, paralleling the DD stage [29]. Indeed, the content of type I (mature) collagen progressively decreases, whilst type III (immature) accumulates, as does the cross-linking among fibers [29]. This shifting was linked to a perturbation of metalloproteinase (MMP-1 and MMP-2) function due to increased production of their inhibitors. More specifically, an 18- and 3-fold increase of MMP-1 and MMP-2 inhibitors, respectively, has been found in $\mathrm{DD}$, so that the normal collagen synthesis is not balanced by an appropriate demolition [29]. Notably, similar alterations have been demonstrated in both Crohn's disease and collagenous colitis [30]. Besides collagen, other alterations in the matrix microenvironment have been found in the colon wall with diverticula. Intriguingly, angiogenic factors (vascular endothelial growth factor, endothelial and smooth muscle derived-neuropilin, MMP-13), cell proliferation regulators (p53, p27, c-erb-2, cyclin D1), and cyclooxygenase-2 were found to be equally expressed in colon with either DD or CRC [31].

Altered colonic pressure profiles were commonly thought to play a role in the etiology and pathophysiology of DD [32]. However, a review showed that there was only a limited volume of literature investigating pressure in patients with diverticulosis [33]. Indeed, pooled data from the existing studies showed no difference in intrasigmoid pressure or the duration of activity when patients with diverticulosis/DD were compared with controls, suggesting that there is only weak evidence to support the role of characteristic patterns of pressure activity in this condition [33]. Nevertheless, more recent findings demonstrated alterations in the enteric neural function. An experimental study found cholinergic denervation hypersensitivity in DD patients compared with controls, due to a lower choline acetyltransferase activity, upregulation of M3 receptors, and increased sensitivity to exogenous acetylcholine [34]. A disturbed glial cell line-derived neurotrophic factor responsiveness was proposed as a contributory factor to the development of these alterations [35]. In addition, the presence of interstitial cells of Cajal, gut pacemaker cells and glial cells was found to be decreased in colonic DD [36]. All these neural abnormalities, overall configuring an "enteric neuropathy", lead to disturbed motility and visceral hypersensitivity in the sigmoid tract, which, in turn, may be responsible, at least in part, for some abdominal symptoms in DD patients [37]. Therefore, DD might be considered as a "transumural" rather than a "mucosal" disease.

Recent data suggest a certain genetic predisposition towards developing diverticulosis and diverticulitis [38,39]. 
Notably, some loci involved in neuromuscular regulation, as well as vascular and mesenchymal (matrix biology, cell adhesion, membrane transport) functions, were detected more frequently in DD patients than in controls.

\section{Diet and lifestyle}

Different lifestyle factors affecting DD manifestations have been identified. The most consistent data, all originating from post hoc analysis, derive from 3 large, longlasting cohort studies [40-43]. These include the Health Professionals Follow-up Study with 47,888 male subjects and 6-year follow up [40], the European Prospective Investigation into Cancer and Nutrition with 47,033 male/female and 11.6-year follow up [41], and the Swedish Mammography Cohort with 36,592 female and 13-year follow up [42]. The main available evidence concerning the protective or aggressive role of lifestyle factors is briefly summarized in Fig. 2. However, the available data need to be interpreted with caution when considering that a factor may: a) act over decades; b) change in the same subject during life; c) exert a diverse role in a different phase of DD; and d) interact with other factors. It has been found that higher serum levels of vitamin $\mathrm{D}$ are associated with a reduced risk of diverticulitis development [43]. Moreover, vitamin D concentrations are linked to the endoscopic severity of DD patients with more severe disease showing significantly lower scores [44]. On the other hand, no significant role emerged for vitamin $\mathrm{A}$, vitamin $\mathrm{C}$, coffee consumption, sodium or potassium [27-31,34-37,40-43].

A systematic review and meta-analysis found that the risk of colonic diverticulosis in current smokers was significantly higher than in non-smokers, with a pooled risk ratio (RR) of 1.46 (95\% confidence interval [CI] 1.13-1.89), whilst the risk in former smokers was not significantly higher (RR 1.13, 95\%CI 0.88-1.44) [45]. Another systematic review and meta-analysis found that the risk of colonic diverticulosis in obese subjects was significantly higher than in those without obesity, with a pooled odds ratio (OR) of 1.41 (95\%CI 1.20-1.65), but with a high heterogeneity [46]. Diabetes mellitus was also found to be a risk factor for patients with DD. A meta-analysis including 17 studies and involving 8,212 patients with diabetes and 381,579 controls, found that patients had approximately 1.2 times (95\%CI 1.135-1.270) higher colonic DD morbidity in prospective studies, as well as an increased risk of colonic diverticular hemorrhage (OR 1.53, 95\%CI 1.14-2.04) [47]. Probably the most clinically relevant amendment was that seeds and nuts, which physicians historically encouraged DD subjects to exclude from their diet to avoid a (never proven) diverticulitis, not only were not dangerous, but were inversely associated with diverticulitis onset and bleeding [40]. Recently, the role of fiber as a protective factor against DD development has been questioned. A case-control study [48], found no association between dietary fiber intake and diverticulosis (OR 0.96, 95\%CI 0.71-1.30) in comparing the highest quartile with

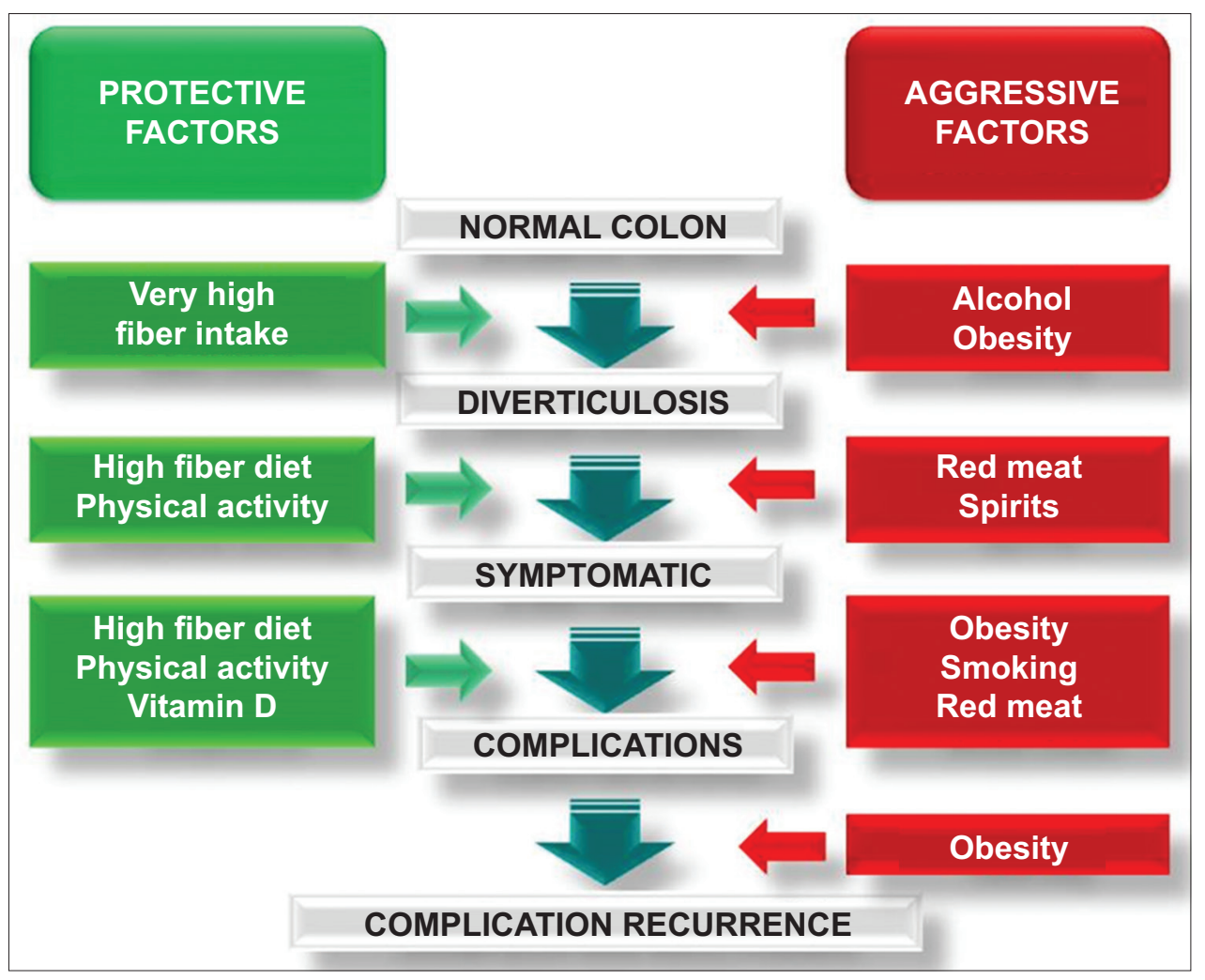

Figure 2 Protective or aggressive role of different lifestyle factors 
the lowest (mean intake: 25 vs. 8 g/day). Furthermore, a recent systematic review found that single low-quality studies suggested that fibers, both dietary and supplemental, could be beneficial in the treatment of SUDD [8]. However, methodological limitations, the heterogeneity of the therapeutic regimens employed, and the lack of ad hoc designed studies did not permit a summary of the outcome measures. Therefore, high-quality evidence on the efficacy of fiber treatment for the reduction in the symptoms of SUDD and for the prevention of acute diverticulitis is lacking, and well-designed studies are needed, specifically focusing on the efficacy of fiber [8].

\section{Drugs and DD complications}

The onset of DD complications significantly increases 1-year mortality, with a hazard ratio (HR) of 4.55 (95\%CI 3.74-5.52) for perforation/abscess, 2.60 (95\%CI 1.47-4.62) for fistula, and 2.41 (95\%CI 1.86-3.11) for stricture [49]. Therefore, to identify, and possibly eliminate, risk factors is clinically advantageous. There is accumulating evidence that some drugs may play a deleterious role in DD, particularly in causing complications such as acute diverticulitis, bleeding and perforation. Recent studies have suggested a relationship between the use of non-steroidal anti-inflammatory drugs (NSAIDs) or steroids and colonic diverticular complications [50,51]. A systematic review and metaanalysis, including data from 6 studies ( 5 case-control studies with 260 cases and 317 controls; 1 cohort study with 58 cases) showed that both NSAIDs (RR 2.24, 95\%CI 1.63-3.09) and aspirin (RR 1.73, 95\%CI 1.31-2.30) significantly increased colonic diverticular bleeding [52]. Another systematic review and meta-analysis found increased odds of perforation and abscess formation with NSAIDs (OR 2.49, 95\%CI 1.98-3.14), steroids (OR 9.08, 95\%CI 3.49-23.62) and opioids (OR 2.52, 95\%CI 1.77-3.57) [53]. The authors also found increased odds of diverticular bleeding from NSAIDs (OR 2.69, 95\%CI 1.65-4.40), aspirin (OR 3.24, 95\%CI 1.59-6.59) and calciumchannel blockers (OR 2.50, 95\%CI 1.44-4.35). However, most studies did not describe the duration or dosage of medication used and did not systematically describe the severity of diverticular complications [53].

Likewise, a recent retrospective study of 1803 Japanese patients found that both NSAIDs $(11 \%$ vs. $5 \%$; $\mathrm{P}<0.01)$ and anti-thrombotic $(28.9 \%$ vs. $15 \% ; \mathrm{P}<0.01)$ therapies were more frequent in patients with diverticular hemorrhage than in 1530 patients with other causes of bleeding ( $11 \%$ vs. $5 \%, \mathrm{P}<0.01$; and $28.9 \%$ vs. $15 \%, \mathrm{P}<0.01$, respectively) [54]. Therapy with tocilizumab (anti-IL6), but not with anti-TNF biologic therapy, was associated with an incidence of 3.9 per 1,000 patients/ year for diverticulitis and 2.69 per 1000 patients/year for lower gastrointestinal perforation in patients with rheumatoid arthritis [55]. Notably, these events occurred with only mild abdominal symptoms and without CRP elevation, challenging a prompt diagnosis.

\section{Role of different diagnostic tools}

\section{Radiology}

In the past, a barium enema (BE) was the leading radiological examination for investigating abdominal symptoms. The accuracy of this procedure for assessing diverticula in the colon has been largely demonstrated [56]. However, since simultaneous neoplastic lesions, i.e., diverticulitis mimicked by cancer, were missed in a definite number of patients, BE is now considered as an obsolete diagnostic test and has been largely replaced by ultrasound (US), computed tomography (CT), and computed tomography colonography (CTC) [57,58]. In patients with suspected diverticulitis, US is regarded as a first-line radiologic test, being noninvasive, fast, low-cost, widely available, easily accessible even within the emergency department, and safe, particularly in young females in whom radiation exposure should be avoided [59]. Another advantage of US is the ability to correlate imaging findings with the region of greatest tenderness in real time. Relative disadvantages of ultrasound include the operator dependence and difficulties in the evaluation of deep abdominal sites, especially in obese patients [59]. US may be used for differential diagnosis with other diseases, in classifying the diverticulitis stage and in monitoring abscess evolution following therapy $[60,61]$. In addition, contrast-enhanced US could play a role in the diagnosis of diverticulitis complications, such as fistulas or covered perforations [59].

CT scan is largely used in the acute setting, allowing differential diagnosis among several diseases that may potentially cause severe abdominal pain $[14,62]$. Specific radiological criteria have been established for the diagnosis of acute diverticulitis without complications (diverticula; bowel wall thickening $>5 \mathrm{~mm}$; pericolonic fat stranding) [59]. CT is highly accurate in assessing diverticulitis complications, as well as in predicting the risk of surgical treatment during the initial acute episode [14]. Moreover, this tool allows the guided drainage of abscesses that have sufficient size $(>5 \mathrm{~cm})$ and are in a favorable location [13]. A recent study showed that $\mathrm{CT}$ is also useful in identifying and guiding therapy in some patients with diverticular bleeding [63]. Indeed, the finding of extravasation on contrast-enhanced CT was associated with a significantly higher detection of the bleeding diverticulum on colonoscopy, as compared to those without extravasation (12/20, $60 \%$ vs. $11 / 35,31 \%$; $\mathrm{P}<0.05)$ [63]. Finally, one study found that CTC was accurate ( $86.5 \%$ sensitivity and $83.1 \%$ specificity) as compared to colonoscopy in detecting diverticula and assessing their distribution through the colon, and DD presence did not degrade the diagnostic performance of CTC for polyp ( $>6 \mathrm{~mm}$ ) detection [64]. Recent British guidelines on the diagnosis and management of acute lower gastrointestinal bleeding (LGIB) recommend that, if a patient is hemodynamically unstable or has a shock index (heart rate/systolic blood pressure) of $>1$ after initial resuscitation and/or active bleeding is suspected, CT angiography provides the fastest and least invasive means of locating the site of blood loss before planning endoscopic or radiological therapy (strong recommendation, low quality evidence) [65]. 


\section{Endoscopy}

The role of colonoscopy in diverticulitis has been largely amended [66]. In 1999, the American College of Gastroenterology's guidelines suggested avoiding colonoscopy in those patients suspected of having acute diverticulitis, given the increased risk of perforation at insufflation [67]. Subsequently, it has been found that early colonoscopy during admission (median time: 5.8 [range: 4-12] days) may be useful and uneventful, the procedure being stopped when a diagnosis of diverticulitis was confirmed. Indeed, the examination was judged beneficial in $17.4 \%$ of cases with a more protracted course of diverticulitis ( $>7$ days antibiotic therapy), through finding other diseases ( 3 cancers and 1 bone stuck in the diverticulum) [57]. Colonoscopy is advocated 6 weeks following acute diverticulitis to ensure that malignancy is not missed [68]. However, recent data cast doubt on the usefulness of this practice, particularly in patients who have uncomplicated diverticulitis or are aged $<55$ years, in whom the presence of cancer is less likely $[69,70]$.

One of the most common causes of LGIB is DD [71,72]. Nevertheless, data concerning the utility of an early endoscopy in patients with diverticular bleeding are scanty. A pivotal trial published in 2000 found that, among patients with severe hematochezia and diverticulosis, at least one fifth have definite diverticular hemorrhage on colonoscopy performed at the bedside $6-12 \mathrm{~h}$ after hospitalization or the diagnosis of hematochezia. It was concluded that endoscopic treatment of these patients might prevent recurrent bleeding and decrease the need for surgery [73]. More recently, a retrospective cohort study aimed to evaluate the impact of the timing of colonoscopy on outcomes in patients with acute diverticular bleeding [74]. It was found that the length of stay in hospital was significantly lower in patients with colonoscopy performed within $24 \mathrm{~h}$ of admission as compared to those with late colonoscopy ( 3.7 vs. 5.6 days; $\mathrm{P}<0.0001$ ). Total hospitalization costs were also significantly lower in patients with early colonoscopy ( $\$ 9317$ vs. $\$ 11,767 ; \mathrm{P}<0.0001$ ). However, there was no difference in mortality between the groups $(0.7 \%$ vs. $0.8 \%$ ) [74]. This finding was consistent with the results of 2 systematic reviews and meta-analyses that aimed to compare several outcomes between urgent and elective colonoscopy in patients hospitalized for LGIB $[75,76]$. Indeed, these reviews did not find any difference in mortality or rebleeding, or in the identification of the bleeding source, in patients with LGIB who underwent an early colonoscopy. In contrast, a meta-analysis of non-randomized studies demonstrated higher diagnostic and therapeutic yields with early colonoscopy (OR 1.86, 95\%CI 1.12-2.86; $\mathrm{P}=0.004$; and $\mathrm{OR} 3.08,95 \% \mathrm{CI} 1.93-4.90 ; \mathrm{P}<0.001$, respectively) and a shorter length of stay (mean difference 2.64 days, 95\%CI 1.54-3.73), but no difference in transfusion or rebleeding [77]. The British Society of Gastroenterology's recent guidelines on the diagnosis and management of acute LGIB suggest stratifying patients as unstable or stable. For unstable patients, it is recommended to perform CT angiography, as it provides the fastest and least invasive means of locating the site of blood loss before planning endoscopic or radiological therapy. Stable patients should be categorized as major or minor, using a risk assessment tool. Patients with a major bleed should be admitted to hospital for colonoscopy on the next available list, whilst patients with a minor self-terminating bleed, with no other indications for hospital admission, can be discharged for urgent outpatient investigation [65].

As an endoscopic classification of DD was lacking, an endoscopic score was recently proposed and validated [78]. The "Diverticular Inflammation and Complication Assesment" (DICA) takes into consideration several scored items (extent of diverticulosis, number of diverticula per region, presence of inflammatory signs, and occurrence of complications) and related sub-items, the sum of which yields 3 different DICA scores (DICA 1, DICA 2, and DICA 3). An international, retrospective study found that DICA was the only factor significantly associated with the occurrence/recurrence of diverticulitis and surgery, on either univariate $(\mathrm{P}<0.0001)$ or multivariate analysis ( $\mathrm{HR} 4.3,95 \% \mathrm{CI}$ 3.6-5.1; $\mathrm{P}<0.0001$ ). Furthermore, it was found that only DICA 2 patients received a benefit from scheduled therapy in preventing the occurrence/recurrence of acute diverticulitis [79]. This score could be useful for the homogenous classification of patients in clinical trials, as well as for identifying patients at higher risk of complications and/or relapse in clinical practice, but further large prospective studies are necessary to confirm these results. Finally, the possibility of converting the DD status into a normal colon by clipping each diverticular sac during endoscopy was recently pioneered. In a pilot study, 9 patients with previous diverticular bleeding underwent elective closure of diverticula with endoclips (median 17.5 clips), and resolution was confirmed in $87.2 \%$ of clipped diverticula in a short-term follow up (median: 4 [range: 3-14] months) [9]. Long-term follow up for assessing relapse and large trials are needed to confirm this very interesting result.

\section{Laboratory}

CRP and white blood cell (WBC) count are largely used to assess acute inflammatory status due to different causes. The Dutch College of General Practitioners' guideline on diverticulitis recommends CRP testing, even using an in-office device, when specific signs and/or symptoms are present, with concentrations of $>20 \mathrm{mg} / \mathrm{L}$ and $>100 \mathrm{mg} / \mathrm{L}$ supporting the diagnosis of uncomplicated and complicated diverticulitis, respectively [80]. However, data from other studies suggest that perforation is unlikely in acute sigmoid diverticulitis when CRP is $<50 \mathrm{mg} / \mathrm{L}$, whereas only values $>200 \mathrm{mg} / \mathrm{L}$ are a strong indicator of perforation [81]. Elevated WBC $(>10,000 / \mathrm{dL})$ showed an $88 \%$ sensitivity and $44 \%$ specificity for diverticulitis perforation [81]. However, a WBC count $>12,000$ was adopted as cutoff for diagnosing acute diverticulitis in several studies $[12,62]$. A WBC count $>10,000-15,000 / \mathrm{dL}$, and $\mathrm{CRP} \geq 50 \mathrm{mg} / \mathrm{L}$ had an OR for diagnosis of acute diverticulitis of 2.53 and 3.78 , respectively [82]. A recent study found that a procalcitonin value $>0.1 \mathrm{ng} / \mathrm{L}$ has $81 \%$ sensitivity and $91 \%$ specificity for differentiating complicated and uncomplicated diverticulitis when combined with abdominal CT scans [83]. It has been also found that hyponatremia $(<136 \mathrm{mg} / \mathrm{L})$ was 
significantly associated with diverticulitis (or appendicitis) perforation in patients older than 50 years [84]. In 2009, Tursi et al published the first study showing increased semiquantitative levels of fecal calprotectin in patients with either uncomplicated diverticulitis or SUDD, but not in asymptomatic DD, IBS patients or controls [85]. However, the accuracy of fecal calprotectin testing in distinguishing different gastrointestinal diseases has been questioned [86].

\section{Predictive scores}

The clinical diagnosis of diverticulitis is challenging in clinical practice, and a misdiagnosis rate ranging between $34 \%$ and $68 \%$ has been reported in the literature [82]. Therefore, some scores based on clinical, laboratory, imaging or surgical data (single or combined) have been proposed to predict the diagnosis, grading severity or recurrence of diverticulitis. The possibility of improving the diagnosis of diverticulitis in the emergency department without imaging has been assessed in two studies. In the first, direct tenderness only in the left lower quadrant, the absence of vomiting, and CRP $>50 \mathrm{mg} / \mathrm{L}$ were found to be predictive of diverticulitis with a high specificity (98\%; positive predictive value: $97 \%$ ), but low sensitivity (36\%; negative predictive value: 47\%) [87]. In the second study, a nomogram including 7 variables (age, previous episodes, localization of symptoms in the lower left abdomen, aggravation of pain on movement, the absence of vomiting, tenderness in the lower left abdomen, and CRP level) was generated, showing an $86 \%$ diagnostic accuracy for acute diverticulitis [82]. When both these scores were validated in another study, specificity and sensitivity were $98-100 \%$ and $14-24 \%$, respectively [88]. Therefore, when these scores are positive, a diagnosis of diverticulitis may reasonably be made even without an imaging study. However, negative values are insufficient reason for excluding the disease.

A meta-analysis evaluating predictors to diagnose complicated diverticulitis showed that first episode, comorbidities (Charlson score 3), NSAID or steroid use, high CRP levels, and severe disease on radiological imaging, but not age or sex, were associated with disease severity [89]. Moreover, the need for surgery in patients with acute diverticulitis was found to be associated with the finding of distant intraperitoneal air on a CT study [90].

Recurrence of diverticulitis occurs in a definite quota of patients. A history of diverticulitis (HR 3.3), abscess (HR 6.2), or corticosteroid medication (HR 16.1) were independent risk factors for complicated recurrence (area under the curve $=0.80$ ), and a score including those parameters was able to identify patients with a low or high risk of developing recurrent diverticulitis during a 5-year follow up that occurred in $3 \%$ and $43 \%$ of cases, respectively [91].

The Hinchey classification, based on intraoperative findings and the Ambrosetti classification, based on CT, are the mostused scoring systems in perforated diverticulitis [14,92,93]. A modified stage IV disease of Hinchey's classification has been recently proposed [94]. Specifically, taking into account the underlying bowel status, primary closure without a diverting stoma could be performed in those patients with a healthy bowel segment [94]. CT grading (moderate or severe) according to Ambrosetti's classification was found to be a significant prognostic parameter for both need for surgery and a secondary complicated outcome after a first acute diverticulitis episode had been successfully treated medically [14].

The endoscopic DICA score has been proposed as a potential tool for DD prognosis [95], and for selecting those patients requiring medical treatment [96]. However, large further prospective studies are needed to consolidate these findings.

\section{Diverticulitis}

\section{Pathogenesis}

Undeniably, acute diverticulitis management is the field of DD that, more than any other, has been subject to major amendments in recent years. However, the real cause of diverticulitis onset still remains speculative. Diverticulitis consists in the inflammation of a diverticulum causing a combination of symptoms, including acute abdominal pain (typically in the lower left quadrant in Caucasian patients), fever, bowel movement alterations, whilst stool blood is generally absent or modest [97]. In the past, the inflammation was attributed to a primary infection of a diverticular sac, potentially leading to a perforation. However, no specific pathogen was demonstrated to cause diverticulitis. To date, diverticulitis is commonly considered an acute inflammation due to traumatic lesions of diverticular mucosa caused by fecolith impaction, particularly in a large diverticular sac, with micro-erosions. Bacterial infection then develops until micro-perforation occurs [97-99]. Recently, the role of ischemic damage, without involvement of fecoliths or infection, has been pointed out [100]. According to this novel hypothesis, there is a temporary (or recurrent) compression of vasa recta in the "neck" of the diverticulum due to a prolonged and/or marked contractile spike of colon with ischemia, particularly in diminutive diverticula, than microperforation at the apex of the sac occurs, with or without secondary infection from fecal bacteria [100]. Clearly, these hypothetical "traumatic" and "ischemic" mechanisms are not mutually exclusive.

\section{Acute uncomplicated diverticulitis (AUD)}

The management of patients with AUD has undergone several modifications in terms of hospital admission, antibiotic administration and surgical intervention. A recent systematic review found that selected patients with the mild form of AUD, without relevant comorbidities or risk factors for complications, might be safely managed without hospital admission, with an average cost saving that ranged from 
$42-82 \%$ compared to inpatient treatment [101,102]. Some recent studies highlighted that some AUD patients may be treated with conservative therapy without antibiotics [103]. The American Gastroenterological Association's guidelines suggest that antibiotics should be used selectively, case by case, rather than routinely as in the past, but the grade of recommendation was conditional and the quality of evidence low [68]. A recent meta-analysis of 8 studies found no difference in treatment outcome, readmission rate, diverticulitis complications, or need for elective or emergent surgery between AUD patients treated with or without antibiotics [103]. However, only 2 randomized studies, both from Scandinavia, were included, whilst all the others were retrospective, non-randomized studies. Therefore, the data should be interpreted with caution, since at entry the enrolled patients were not comparable in terms of several clinical characteristics, based on which the choice of treatment (antibiotic or conservative) was arbitrarily applied by the clinician. Data from ongoing randomized controlled trials are awaited [104]. When antibiotic therapy is deemed necessary, some concerns may arise about both therapy duration and route of administration. It has been found that a 5-day course of antibiotic therapy with ceftriaxone and metronidazole i.v. is equally effective to a 5-10 day course [105]. Moreover, some studies have challenged the traditional concept of treating acute diverticulitis with intravenous antibiotic therapy, instead proposing that oral antibiotic therapy may be appropriate [106,107]. A randomized controlled trial found no difference in the outcome of AUD patients treated with ciprofloxacin and metronidazole administered orally or i.v. [106].

\section{Surgical approach}

The decision-making process for the surgical approach to diverticulitis has been greatly modified in the last decade. AUD may recur in up to $20 \%$ of patients, and successive episodes were deemed to be riskier than the first in terms of complications and overall outcome [108]. Therefore, based on some decisional-model data, surgery was advised following 1 or 2 episodes of AUD, particularly in young patients and the obese, who are at increased risk for recurrence [107]. However, more recent studies showed that the outcome of diverticulitis recurrence did not appear to be worse than that of the first episode; thus, the need for surgery in every patient has been questioned [3,109]. Indeed, a certain cohort of selected patients with even complicated diverticulitis may be safely managed without surgical intervention [110]. A systematic review found that only $6 \%$ of patients with isolated pericolic extraluminal air needed emergency surgery within the acute diverticulitis episode, so that an initial conservative approach is also advocated in these patients when risk factors (immunosuppression, NSAID use) were absent [111]. However, a randomized trial found that the recurrence rate of complicated diverticulitis is significantly higher following conservative treatment (32\%) than after elective surgical resection (8\%) in patients with acute diverticulitis complicated by an abscess [112].

\section{SUDD and IBS: an unsolved dilemma}

The Italian consensus conference on colonic diverticulosis and DD defines SUDD as "a syndrome characterized by recurrent abdominal symptoms (i.e., abdominal pain and bloating resembling or overlapping IBS symptoms) attributed to diverticula in the absence of macroscopically evident alterations other than the presence of diverticula" [113]. This definition recognizes the difficulty of differentiating this entity from IBS. Indeed, IBS and DD are common conditions in Western Europe and North America [114,115]. The diagnosis of IBS, according to Rome IV, is based on well-defined and precise criteria [116]. In contrast, the term "diverticular disease" lacks a truly meaningful definition (in clinical terms) and has been loosely applied to a wide spectrum of diseases [117].

The epidemiology of SUDD is still largely unknown. One survey aimed to assess the clinical features associated with SUDD [118]. It was found that SUDD had an unspecific clinical picture, mainly characterized by normal stools, short-lived abdominal pain, abdominal bloating and IBS-like symptoms, while functional dyspepsia-like symptoms were not commonly present [118]. An ongoing Italian prospective, observational, multicenter, cohort study found that female sex was significantly associated with SUDD (OR 1.94, 95\%CI 1.43-2.62) and with a lower quality of life compared to those with diverticulosis (physical component: $\mathrm{P}=0.0001$; mental component: $\mathrm{P}<0.0001)$ [119].

Another multicenter study aimed to verify whether clinical features can distinguish DD from IBS [120]. Only $10 \%$ of patients with DD fulfilled the criteria for IBS diagnosis according to the Rome III criteria. However, if the criterion "time from onset: at least 6 months" was excluded, $66 \%$ of patients with DD complained of IBS-like symptoms. Compared to patients with IBS, patients with DD consumed less coffee $(\mathrm{P}=0.04)$, but more dietary fiber $(\mathrm{P}=0.002)$, and had significantly greater first-degree inheritance for $\mathrm{DD}(\mathrm{P}=0.001)$ and CRC $(\mathrm{P}=0.05)$, as well as higher rates of diabetes $(\mathrm{P}=0.04)$ and dyslipidemia $(\mathrm{P}=0.03)$. Diarrhea was more common in patients with IBS $(32 / 90 ; 36 \%)$ compared to patients with DD $(14 / 90 ; 14 \% ; \mathrm{P}<0.001)$, whilst bloating was similar in both DD $(68 \%)$ and IBS $(56 \%)$ patients $(\mathrm{P}=0.12)$. The prevalence of abdominal pain was similar in both groups. When the duration of the abdominal pain was considered, pain lasting $<24$ h was reported significantly more frequently by patients with DD than patients with IBS $(\mathrm{P}<0.01)$, but assessment of severity by visual analog scale did not detect significant differences between the groups. Abdominal pain lasting $>24 \mathrm{~h}$ was also significantly more frequent in DD $(20 / 90 ; 22 \%)$ than in IBS patients $(6 / 90,7 \%$; $<<0.01)$ and pain was very severe in a significantly $(\mathrm{P}<0.01)$ higher number of patients with DD. Authors concluded that only abdominal pain lasting more than $24 \mathrm{~h}$ characterizes patients with DD compared to those with IBS [120]. However, this proposal needs confirmation by future, large studies.

The use of fecal calprotectin in discriminating SUDD from IBS has also been proposed [85]. Using a semi-quantitative test, it was found that fecal calprotectin was positive in 
$27(64.3 \%)$ patients with symptomatic DD and in none of the 30 IBS patients [121]. In contrast, a multicenter study that included 105 patients with DD and 349 without any lesion at colonoscopy found that mean calprotectin levels did not differ between groups, and a positive value ( $>50 \mathrm{mg} / \mathrm{dL}$ ) was equally detected in $36 \%$ of cases [86]. In addition, fecal calprotectin test was positive in $39.1 \%$ of 616 consecutive IBS patients [122]. Therefore, the proposed use of the fecal calprotectin test needs to be validated in large studies. Indeed, it is unclear why calprotectin levels should be increased in SUDD, but not in IBS patients, when we consider that a mild, microscopic inflammation of colonic mucosa has also been detected in IBS patients [28].

Taking all these data into account, the relationship between SUDD and IBS remains unsolved and it is clear that highquality prospective studies of well-phenotyped individuals are needed. To date, the therapeutic implications of relationships between DD and IBS remain few and, consequently, far from capable of guiding clinical management [117].

\section{DD and CRC}

An intriguing relationship between DD and CRC has been pointed out in recent decades. Likewise, similar risk factors, such as advanced age, some lifestyle behaviors and diet, are shared by both conditions. However, there is conflicting evidence. A United States study with 624 participants who underwent screening colonoscopy, including 260 with DD, showed that the risk of adenoma or advanced adenoma was not increased in DD patients [10]. In contrast, a similar study performed in Italy on 970 subjects, including 354 with DD, found that the presence of diverticula was an independent risk factor in multivariate analysis for both adenoma detection rate $(\mathrm{OR} 1.58,95 \% \mathrm{CI} 1.14-2.18 ; \mathrm{P}=0.006)$ and advanced adenoma (OR 1.57, 95\%CI 1.10-2.24; $\mathrm{P}=0.013$ ), but not for CRC [7]. A cross-sectional endoscopic study performed in China found no association between right-sided DD (2.4\%) and adenomas (13.2\%) [123]. A systematic review of 10 studies with 22,721 cases showed a significant association in only half of the included series, so that it was concluded that the available data were not consistent; this highlighted the need for further studies [124]. Recently, a systematic review and meta-analysis of observational studies was published that aimed to assess the prevalence of CRC in patients with acute diverticulitis [125]. The prevalence of CRC was $1.9 \%$ (95\%CI 1.5-2.3), and patients with complicated diverticulitis had a significantly higher risk for CRC (7.9\%, 95\%CI 3.9-15.3) than patients with uncomplicated diverticulitis $(1.3 \%$, 95\%CI $0.1-2)$, corresponding to a pooled prevalence ratio of 6.7 (95\%CI 2.5 18.3). This suggested the utility of performing a postponed colonoscopy after an episode of diverticulitis applied only to the subgroup with complicated diverticulitis. Subgroup analyses did not find significant differences in prevalence when studies were pooled separately according to ranking on the NewcastleOttawa scale, geographical location or length of follow up. Meta-regression did not find any association between age and
CRC. Among patients who underwent endoscopy, the pooled prevalence was $22.7 \%$ for polyps (95\%CI 19.6-26.0), $4.4 \%$ for advanced adenomas (95\%CI 3.4-5.8), 14.2\% for adenomas (95\%CI 11.7-17.1), and 9.2\% for hyperplastic polyps (95\%CI 7.6-11.2). Therefore, based on these observations, there are not yet sufficiently strong data to suggest more aggressive CRC prevention or follow up in DD compared with non-diverticular subjects.

\section{Other clinical entities}

\section{SCAD}

SCAD is defined as a macroscopic and microscopic inflammation limited to the crests of mucosal folds in the diverticular tract, and sparing diverticula [126]. It is characterized by a wide spectrum of clinical, pathological and endoscopic features, some of them still poorly defined. Indeed, it may present as anything from asymptomatic superficial areas of erythema detected on endoscopy to severe lesions resembling IBD. Likewise, the clinical course may be selflimiting [127] or may evolve into a clear IBD requiring biologic therapy [128]. At first it was considered to belong within the spectrum of DD manifestations, so that it is currently included in the endoscopic DICA classification [78]. Nevertheless, in the more recent literature, SCAD was considered as a chronic colitis in the spectrum of IBD, rather than in DD, which develops in genetically predisposed subjects, and the management of patients with severe forms is analogous to that of IBD patients [129].

\section{Asymptomatic acute diverticulitis}

Unexpected asymptomatic acute diverticulitis was identified in $21(0.82 \%)$ of 2566 consecutive patients presenting for elective colonoscopy. Endoscopic features included granulation tissue protruding from a diverticular orifice, erythema and edema, or pus of a single diverticulum. Only 1 of these patients complained of abdominal pain before endoscopy, and none developed definite diverticulitis at 1-year follow up [130]. Therefore, the clinical relevance of this endoscopic feature still remains unclear.

\section{Chronic diverticulitis}

The definitions of "chronic diverticulitis" and "chronic recurrent diverticulitis" firstly appeared in a novel taxonomic classification proposed in 2012 [131]. According to this proposal, chronic diverticulitis is characterized by a microscopic inflammation-lymphocytes infiltrate within and around diverticula of patients without overt diverticulitis or colitis-that might contribute to symptom development in some patients with DD. This was derived from data of 
some studies showing that such a condition was present on 16 (94\%) random biopsies taken in 17 DD patients without macroscopic lesions [132], and in 75\% resected specimens from 930 patients undergoing surgery for SUDD without overt diverticulitis [133]. Based on these findings, the large majority of DD patients harbor a mild chronic inflammation in the colonic mucosa, but less than $20 \%$ of subjects complain of abdominal symptoms [1]. As discussed above, the role of this mild increase in the lymphocyte infiltrate of DD mucosa in generating abdominal symptoms remains to be proven.

\section{Concluding remarks}

In the last decade, several concepts related to the diagnostic, clinical and therapeutic approaches to the management of DD patients have significantly changed. Some alterations of colonic mucosa, such as deposition of abnormal collagen in colonic wall, and the tendency to develop fistula and abscess, would render DD more similar to Crohn's disease than to ulcerative colitis. Indeed, DD might be considered as a "transmural" rather than "mucosal" colonic disease $[37,134]$. Remarkably, these aspects have been overlooked in the proposed therapeutic approaches, mainly based on either luminal (non-absorbable antibiotics, probiotics) or mucosal (mesalazine) therapies. Alterations of colonic motility, due to the well-documented cholinergic denervation hypersensitivity, are expected to be involved in some abdominal symptoms, including pain and bowel habit disturbance. However, they remain largely neglected in the therapeutic approaches to symptomatic DD patients in clinical practice [135]. Experimental data have clearly demonstrated that hyper-contractions of circular muscle in the sigmoid tract with DD are reduced by anticholinergic drugs, although a high dose may be necessary [100]. Unfortunately, only data from old, and often not well-designed, studies are available, and the scant interest of pharmaceutical industries in research in this field appears to be unjustified. Apart from NSAIDs and steroids, the role of various drugs involved in the development of DD complications has emerged in recent years [53]. Some of these therapies are widely used in clinical practice, particularly in elderly patients, who frequently harbor diverticula in their colon. Therefore, more attention should be paid to the management of DD patients receiving multiple therapies. The use of antibiotics in AUD has been largely questioned in recent trials, a case-by-case approach being suggested [68]. Nevertheless, identifying risk factors for complications remains a priority, so that preventive therapy with antibiotics could at least be reserved for those patients at high risk. The relationship between SUDD and IBS remains unsolved, and future prospective studies are needed to better characterize these patients [117].

Taking into consideration all data presented, it is clear that a lot still has to be learned regarding this common, costly, and complicated disease ("The dark side of the moon"). Highquality randomized controlled trials need to be performed in patients with $\mathrm{DD}$, specifically devoted to each different clinical condition included in that umbrella term. However, it is difficult to perform these types of study because of a range of factors, such as sample sizes inadequate to detect differences in infrequent but serious events and/or the inability to blind treatment allocation. Well-supported, definitive consensus guidelines do not yet exist, so physicians must often use their clinical judgment to manage and select treatments [3]. The saga will definitely continue!

\section{References}

1. Rustom LBO, Sharara AI. The natural history of colonic diverticulosis: much ado about nothing? Inflamm Intest Dis 2018;3:69-74.

2. Bollom A, Austrie J, Hirsch W, et al. Emergency department burden of diverticulitis in the USA, 2006-2013. Dig Dis Sci 2017;62:2694-2703.

3. Strate LL, Morris AM. Epidemiology, pathophysiology, and treatment of diverticulitis. Gastroenterology 2019;156:1282-1298.

4. Young-Fadok TM. Diverticulitis. $N$ Engl $J$ Med 2018;379:1635-1642.

5. Tursi A, Papa A, Danese S. Review article: the pathophysiology and medical management of diverticulosis and diverticular disease of the colon. Aliment Pharmacol Ther 2015;42:664-684.

6. Rezapour M, Ali S, Stollman N. Diverticular disease: an update on pathogenesis and management. Gut Liver 2018;12:125-132.

7. Morini S, Ridola L, Hassan C, et al. Association between diverticulosis and colonic neoplastic lesions in individuals with a positive faecal immunochemical test. United European Gastroenterol J 2017;5:134-138.

8. Carabotti M, Annibale B, Severi C, Lahner E. Role of fiber in symptomatic uncomplicated diverticular disease: a systematic review. Nutrients 2017;9.

9. Haji A, Plastiras A, Ortenzi M, Gulati S, Emmanuel A, Hayee B. Elective endoscopic clipping for the treatment of symptomatic diverticular disease: a potential for 'cure'. Gut 2019;68:582-584.

10. Peery AF, Martin CF, Levinson SE, Sandler RS. Colonic diverticula are not associated with an increased risk of colorectal adenomas. Am J Gastroenterol 2015;110:1694-1697.

11. Stollman N, Raskin JB. Diverticular disease of the colon. Lancet 2004;363:631-639.

12. Pautrat K, Bretagnol F, Huten N, de Calan L. Acute diverticulitis in very young patients: a frequent surgical management. Dis Colon Rectum 2007;50:472-477.

13. Kaiser AM, Jiang JK, Lake JP, et al. The management of complicated diverticulitis and the role of computed tomography. Am J Gastroenterol 2005;100:910-917.

14. Ambrosetti P. Value of CT for acute left-colonic diverticulitis: the surgeon's view. Dig Dis 2012;30:51-55.

15. Nguyen GC, Steinhart AH. Nationwide patterns of hospitalizations to centers with high volume of admissions for inflammatory bowel disease and their impact on mortality. Inflamm Bowel Dis 2008;14:1688-1694.

16. Katz LH, Guy DD, Lahat A, Gafter-Gvili A, Bar-Meir S. Diverticulitis in the young is not more aggressive than in the elderly, but it tends to recur more often: systematic review and meta-analysis. J Gastroenterol Hepatol 2013;28:1274-1281.

17. Imaeda $\mathrm{H}$, Hibi $\mathrm{T}$. The burden of diverticular disease and its complications: West versus East. Inflamm Intest Dis 2018;3:61-68.

18. Razik R, Nguyen GC. Diverticular disease: changing epidemiology and management. Drugs Aging 2015;32:349-360.

19. Hjern F, Johansson C, Mellgren A, Baxter NN, Hjern A. Diverticular disease and migration - the influence of acculturation 
to a Western lifestyle on diverticular disease. Aliment Pharmacol Ther 2006;23:797-805.

20. Tursi A, Brandimarte G, Elisei W, et al. Assessment and grading of mucosal inflammation in colonic diverticular disease. J Clin Gastroenterol 2008;42:699-703.

21. Tursi A, Elisei W, Brandimarte G, et al. Mucosal expression of basic fibroblastic growth factor, Syndecan 1 and tumor necrosis factor-alpha in diverticular disease of the colon: a case-control study. Neurogastroenterol Motil 2012;24:836-e396.

22. Ma W, Chan AT. Does subclinical inflammation play a role in the pathogenesis of diverticulosis? Clin Gastroenterol Hepatol 2018;16:817-818.

23. Morini S, Hassan C, Zullo A, et al. Epithelial cell proliferation of the colonic mucosa in diverticular disease: a case-control study. Aliment Pharmacol Ther 2005;21:1385-1390.

24. Cianci R, Iacopini F, Petruzziello L, Cammarota G, Pandolfi F, Costamagna G. Involvement of central immunity in uncomplicated diverticular disease. Scand J Gastroenterol 2009;44:108-115.

25. Elli L, Roncoroni L, Bardella MT, et al. Absence of mucosal inflammation in uncomplicated diverticular disease. Dig Dis Sci 2011;56:2098-2103.

26. Peery AF, Keku TO, Addamo C, et al. Colonic diverticula are not associated with mucosal inflammation or chronic gastrointestinal symptoms. Clin Gastroenterol Hepatol 2018;16:884-891.

27. Järbrink-Sehgal ME, Rassam L, Jasim A, et al. Diverticulosis, symptoms and colonic inflammation: a population-based colonoscopy study. Am J Gastroenterol 2019;114:500-510.

28. Corinaldesi R, Stanghellini V, Cremon C, et al. Effect of mesalazine on mucosal immune biomarkers in irritable bowel syndrome: a randomized controlled proof-of-concept study. Aliment Pharmacol Ther 2009;30:245-252.

29. Mimura T, Bateman AC, Lee RL, et al. Up-regulation of collagen and tissue inhibitors of matrix metalloproteinase in colonic diverticular disease. Dis Colon Rectum 2004;47:371-378; discussion 378-379.

30. Meijer MJ, Mieremet-Ooms MA, van der Zon AM, et al. Increased mucosal matrix metalloproteinase-1, $-2,-3$ and -9 activity in patients with inflammatory bowel disease and the relation with Crohn's disease phenotype. Dig Liver Dis 2007;39:733-739.

31. Klinge $\mathrm{U}$, Rosch $\mathrm{R}$, Junge $\mathrm{K}$, et al. Different matrix microenvironments in colon cancer and diverticular disease. Int $J$ Colorectal Dis 2007;22:515-520.

32. Sheth AA, Longo W, Floch MH. Diverticular disease and diverticulitis. Am J Gastroenterol 2008;103:1550-1556.

33. Jaung R, Robertson J, O'Grady G, Milne T, Rowbotham D, Bissett IP. Limited evidence of abnormal intra-colonic pressure profiles in diverticular disease - a systematic review. Colorectal Dis 2017;19:O168-O176.

34. Golder M, Burleigh DE, Belai A, et al. Smooth muscle cholinergic denervation hypersensitivity in diverticular disease. Lancet 2003;361:1945-1951.

35. Barrenschee $\mathrm{M}$, Wedel T, Lange $\mathrm{C}$, et al. No neuronal loss, but alterations of the GDNF system in asymptomatic diverticulosis. PLoS One 2017;12:e171416.

36. Bassotti G, Battaglia E, Bellone G, et al. Interstitial cells of Cajal, enteric nerves, and glial cells in colonic diverticular disease. J Clin Pathol 2005;58:973-977.

37. Spiller R. Diverticular disease and IBS: overlapping or misunderstanding? J Clin Gastroenterol 2016;50 Suppl 1:S29-S32.

38. Maguire LH, Handelman SK, Du X, Chen Y, Pers TH, Speliotes EK. Genome-wide association analyses identify 39 new susceptibility loci for diverticular disease. Nat Genet 2018;50:1359-1365.

39. Schafmayer C, Harrison JW, Buch S, et al. Genomewide association analysis of diverticular disease points towards neuromuscular, connective tissue and epithelial pathomechanisms. Gut 2019;68:854-865.

40. Strate LL, Liu YL, Syngal S, Aldoori WH, Giovannucci EL. Nut, corn, and popcorn consumption and the incidence of diverticular disease. JAMA 2008;300:907-914.

41. Crowe FL, Appleby PN, Allen NE, Key TJ. Diet and risk of diverticular disease in Oxford cohort of European Prospective Investigation into Cancer and Nutrition (EPIC): prospective study of British vegetarians and non-vegetarians. BMJ 2011;343:d4131.

42. Hjern F, Wolk A, Håkansson N. Obesity, physical inactivity, and colonic diverticular disease requiring hospitalization in women: a prospective cohort study. Am J Gastroenterol 2012;107:296-302.

43. Maguire LH, Song M, Strate LL, Giovannucci EL, Chan AT. Association of geographic and seasonal variation with diverticulitis admissions. JAMA Surg 2015;150:74-77.

44. Tursi A, Elisei W, Picchio M, Di Mario F, Brandimarte G. Serum levels of vitamin D are associated with the severity of the endoscopic appearance of diverticular disease of the colon according to DICA classification. J Gastrointestin Liver Dis 2016;25:567-568

45. Wijarnpreecha K, Boonpheng B, Thongprayoon C, Jaruvongvanich V, Ungprasert P. Smoking and risk of colonic diverticulosis: a meta-analysis. J Postgrad Med 2018;64:35-39.

46. Wijarnpreecha K, Ahuja W, Chesdachai S, et al. Obesity and the risk of colonic diverticulosis: a meta-analysis. Dis Colon Rectum 2018;61:476-483.

47. Lin X, Li J, Ying M, Wei F, Xie X. Diabetes increases morbidities of colonic diverticular disease and colonic diverticular hemorrhage: a systematic review and meta-analysis. Am J Ther 2017;24:e213-e221.

48. Peery AF, Sandler RS, Ahnen DJ, et al. Constipation and a lowfiber diet are not associated with diverticulosis. Clin Gastroenterol Hepatol 2013;11:1622-1627.

49. Humes DJ, West J. Role of acute diverticulitis in the development of complicated colonic diverticular disease and 1-year mortality after diagnosis in the UK: population-based cohort study. Gut 2012;61:95-100.

50. Strate LL, Liu YL, Huang ES, Giovannucci EL, Chan AT. Use of aspirin or nonsteroidal anti-inflammatory drugs increases risk for diverticulitis and diverticular bleeding. Gastroenterology 2011;140:1427-1433.

51. Mpofu S, Mpofu CM, Hutchinson D, Maier AE, Dodd SR, Moots RJ. Steroids, non-steroidal anti-inflammatory drugs, and sigmoid diverticular abscess perforation in rheumatic conditions. Ann Rheum Dis 2004;63:588-590.

52. Yuhara H, Corley DA, Nakahara F, et al. Aspirin and non-aspirin NSAIDs increase risk of colonic diverticular bleeding: a systematic review and meta-analysis. J Gastroenterol 2014;49:992-1000.

53. Kvasnovsky CL, Papagrigoriadis S, Bjarnason I. Increased diverticular complications with nonsteriodal anti-inflammatory drugs and other medications: a systematic review and metaanalysis. Colorectal Dis 2014;16:O189-O196.

54. Kinjo K, Matsui T, Hisabe T, et al. Increase in colonic diverticular hemorrhage and confounding factors. World J Gastrointest Pharmacol Ther 2016;7:440-446.

55. Strangfeld A, Richter A, Siegmund B, et al. Risk for lower intestinal perforations in patients with rheumatoid arthritis treated with tocilizumab in comparison to treatment with other biologic or conventional synthetic DMARDs. Ann Rheum Dis 2017;76:504-510.

56. Bar-Meir S, Lahat A, Melzer E. Role of endoscopy in patients with diverticular disease. Dig Dis 2012;30:60-63.

57. Halligan S. CT colonography for investigation of patients with symptoms potentially suggestive of colorectal cancer: a review of the UK SIGGAR trials. Br J Radiol 2013;86:20130137.

58. Flor N, Maconi G, Cornalba G, Pickhardt PJ. The current role of radiologic and endoscopic imaging in the diagnosis and 
follow-up of colonic diverticular disease. AJR Am J Roentgenol 2016;207:15-24

59. Puylaert JB. Ultrasound of colon diverticulitis. Dig Dis 2012;30:56-59.

60. Mizuki A, Nagata $H$, Tatemichi $M$, et al. The out-patient management of patients with acute mild-to-moderate colonic diverticulitis. Aliment Pharmacol Ther 2005;21:889-897.

61. Kandagatla PG, Stefanou AJ. Current status of the radiologic assessment of diverticular disease. Clin Colon Rectal Surg 2018;31:217-220.

62. Rao PM, Rhea JT, Novelline RA, et al. Helical CT with only colonic contrast material for diagnosing diverticulitis: prospective evaluation of 150 patients. AJR Am J Roentgenol 1998;170:1445-1449.

63. Sugiyama T, Hirata Y, Kojima Y, et al. Efficacy of contrastenhanced computed tomography for the treatment strategy of colonic diverticular bleeding. Intern Med 2015;54:2961-2967.

64. Sanford MF, Pickhardt PJ. Diagnostic performance of primary 3-dimensional computed tomography colonography in the setting of colonic diverticular disease. Clin Gastroenterol Hepatol 2006;4:1039-1047.

65. Oakland K, Chadwick G, East JE, et al. Diagnosis and management of acute lower gastrointestinal bleeding: guidelines from the British Society of Gastroenterology. Gut 2019;68:776-789.

66. Tursi A. The role of colonoscopy in managing diverticular disease of the colon. J Gastrointestin Liver Dis 2015;24:85-93.

67. Stollman NH, Raskin JB. Diagnosis and management of diverticular disease of the colon in adults. Ad Hoc Practice Parameters Committee of the American College of Gastroenterology. Am J Gastroenterol 1999;94:3110-3121.

68. Stollman N, Smalley W, Hirano I; AGA Institute Clinical Guidelines Committee. American Gastroenterological Association Institute Guideline on the Management of Acute Diverticulitis. Gastroenterology 2015;149:1944-1949.

69. Lahat A, Yanai H, Sakhnini E, Menachem Y, Bar-Meir S. Role of colonoscopy in patients with persistent acute diverticulitis. World J Gastroenterol 2008;14:2763-2766.

70. Chan DKH, Tan KK. There is no role for colonoscopy after diverticulitis among Asian patients less than 50 years of age. Gastrointest Tumors 2017;3:136-140.

71. Wheat CL, Strate LL. Trends in hospitalization for diverticulitis and diverticular bleeding in the United States from 2000 to 2010. Clin Gastroenterol Hepatol 2016;14:96-103.

72. Oakland K, Guy R, Uberoi R, et al; UK Lower GI Bleeding Collaborative. Acute lower GI bleeding in the UK: patient characteristics, interventions and outcomes in the first nationwide audit. Gut 2018;67:654-662.

73. Jensen DM, Machicado GA, Jutabha R, Kovacs TO. Urgent colonoscopy for the diagnosis and treatment of severe diverticular hemorrhage. N Engl J Med 2000;342:78-82.

74. Saraireh H, Tayyem O, Siddiqui MT, Hmoud B, Bilal M. Early colonoscopy in patients with acute diverticular bleeding is associated with improvement in healthcare-resource utilization. Gastroenterol Rep (Oxf) 2019;7:115-120.

75. Kouanda AM, Somsouk M, Sewell JL, Day LW. Urgent colonoscopy in patients with lower GI bleeding: a systematic review and meta-analysis. Gastrointest Endosc 2017;86:107-117.

76. Seth A, Khan MA, Nollan R, et al. Does urgent colonoscopy improve outcomes in the management of lower gastrointestinal bleeding? Am J Med Sci 2017;353:298-306.

77. Oakland K, Isherwood J, Lahiff C, et al. Diagnostic and therapeutic treatment modalities for acute lower gastrointestinal bleeding: a systematic review. Endosc Int Open 2017;5:E959-E973.

78. Tursi A, Brandimarte G, Di Mario F, et al. Development and validation of an endoscopic classification of diverticular disease of the colon: the DICA classification. Dig Dis 2015;33:68-76.

79. Tursi A, Brandimarte G, Di Mario F, et al; DICA Collaborative
Group: Luigi Di Cesare. Predictive value of the diverticular inflammation and complication assessment (DICA) endoscopic classification on the outcome of diverticular disease of the colon: an international study. United European Gastroenterol J 2016;4:604-613.

80. Schuijt TJ, Boss DS, Musson REA, Demir AY. Influence of pointof-care C-reactive protein testing on antibiotic prescription habits in primary care in The Netherlands. Fam Pract 2018;35:179-185.

81. Käser SA, Fankhauser G, Glauser PM, Toia D, Maurer CA. Diagnostic value of inflammation markers in predicting perforation in acute sigmoid diverticulitis. World J Surg 2010;34:2717-2722.

82. Andeweg CS, Knobben L, Hendriks JC, Bleichrodt RP, van Goor H. How to diagnose acute left-sided colonic diverticulitis: proposal for a clinical scoring system. Ann Surg 2011;253:940-946.

83. Jeger V, Pop R, Forudastan F, Barras JP, Zuber M, Piso RJ. Is there a role for procalcitonin in differentiating uncomplicated and complicated diverticulitis in order to reduce antibiotic therapy? A prospective diagnostic cohort study. Swiss Med Wkly 2017;147:w14555.

84. Käser SA, Furler R, Evequoz DC, Maurer CA. Hyponatremia is a specific marker of perforation in sigmoid diverticulitis or appendicitis in patients older than 50 years. Gastroenterol Res Pract 2013;2013:462891.

85. Tursi A, Brandimarte G, Elisei W, Giorgetti GM, Inchingolo CD, Aiello F. Faecal calprotectin in colonic diverticular disease: a case-control study. Int J Colorectal Dis 2009;24:49-55.

86. Meucci G, D-Incà R, Maieron R, et al. Diagnostic value of faecal calprotectin in unselected outpatients referred for colonoscopy: A multicenter prospective study. Dig Liver Dis 2010;42:191-195.

87. Laméris W, van Randen A, van Gulik TM, et al. A clinical decision rule to establish the diagnosis of acute diverticulitis at the emergency department. Dis Colon Rectum 2010;53:896-904.

88. Kiewiet JJ, Andeweg CS, Laurell H, et al. External validation of two tools for the clinical diagnosis of acute diverticulitis without imaging. Dig Liver Dis 2014;46:119-124.

89. Tan JP, Barazanchi AW, Singh PP, Hill AG, Maccormick AD. Predictors of acute diverticulitis severity: A systematic review. Int J Surg 2016;26:43-52.

90. Shin S, Kim D, Kang UR, Yang CS. Impact of CT imaging on predicting the surgical management of acute diverticulitis. Ann Surg Treat Res 2018;94:322-329.

91. Sallinen V, Mali J, Leppäniemi A, Mentula P. Assessment of risk for recurrent diverticulitis: a proposal of risk score for complicated recurrence. Medicine (Baltimore) 2015;94:e557.

92. Hinchey EJ, Schaal PG, Richards GK. Treatment of perforated diverticular disease of the colon. Adv Surg 1978;12:85-109.

93. Krukowski ZH, Matheson NA. Emergency surgery for diverticular disease complicated by generalized and faecal peritonitis: a review. Br J Surg 1984;71:921-927.

94. Naraynsingh V, Maharaj R, Hassranah D, Hariharan S, Dan D, Zbar AP. Perforated left-sided diverticulitis with faecal peritonitis: is the Hinchey classification the best guide for surgical decision making? Tech Coloproctol 2011;15:199-203.

95. Tursi A, Brandimarte G, Di Mario F, Elisei W, Scarpignato C, Picchio M. Prognostic role of the endoscopic classification "DICA". J Clin Gastroenterol 2016;50 Suppl 1:S16-S19.

96. Tursi A, Elisei W, Picchio $M$, et al. Impact of diverticular inflammation and complication assessment classification on the burden of medical therapies in preventing diverticular disease complications in Italy. Ann Transl Med 2017;5:320.

97. Jacobs DO. Clinical practice. Diverticulitis. N Engl J Med 2007;357:2057-2066.

98. Humes DJ, Spiller RC. Review article: The pathogenesis and management of acute colonic diverticulitis. Aliment Pharmacol Ther 2014;39:359-370. 
99. West AB; NDSG. The pathology of diverticulitis. J Clin Gastroenterol 2008;42:1137-1138.

100. Zullo A. Medical hypothesis: speculating on the pathogenesis of acute diverticulitis. Ann Gastroenterol 2018;31:747-749.

101. Balasubramanian I, Fleming C, Mohan HM, Schmidt K, Haglind E, Winter DC. Out-patient management of mild or uncomplicated diverticulitis: a systematic review. Dig Surg 2017;34:151-160.

102. van Dijk ST, Bos K, de Boer MGJ, et al. A systematic review and meta-analysis of outpatient treatment for acute diverticulitis. Int J Colorectal Dis 2018;33:505-512.

103. Mocanu V, Dang JT, Switzer N, et al. The role of antibiotics in acute uncomplicated diverticulitis: a systematic review and metaanalysis. Am J Surg 2018;216:604-609.

104. Mora Lopez L, Ruiz-Edo N, Serra Pla S, Pallisera Llovera A, Navarro Soto S, Serra-Aracil X; Diverticulitis Study Group. Multicentre, controlled, randomized clinical trial to compare the efficacy and safety of ambulatory treatment of mild acute diverticulitis without antibiotics with the standard treatment with antibiotics. Int J Colorectal Dis 2017;32:1509-1516.

105. Scarpa CR, Buchs NC, Poncet A, et al. Short-term intravenous antibiotic treatment in uncomplicated diverticulitis does not increase the risk of recurrence compared to long-term treatment. Ann Coloproctol 2015;31:52-56.

106. Ridgway PF, Latif A, Shabbir J, et al. Randomized controlled trial of oral vs intravenous therapy for the clinically diagnosed acute uncomplicated diverticulitis. Colorectal Dis 2009;11:941-946.

107. Lee TH, Setty PT, Parthasarathy G, et al. Aging, obesity, and the incidence of diverticulitis: a population-based study. Mayo Clin Proc 2018;93:1256-1265.

108. Humes DJ, Fleming KM, Spiller RC, West J. Concurrent drug use and the risk of perforated colonic diverticular disease: a population-based case-control study. Gut 2011;60:219-224.

109. Al Harakeh H, Paily AJ, Doughan S, Shaikh I. Recurrent acute diverticulitis: when to operate? Inflamm Intest Dis 2018;3:91-99.

110. Fung AK, Ahmeidat H, McAteer D, Aly EH. Validation of a grading system for complicated diverticulitis in the prediction of need for operative or percutaneous intervention. Ann R Coll Surg Engl 2015;97:208-214

111. van Dijk ST, Doelare SAN, van Geloven AAW, Boermeester MA. A systematic review of pericolic extraluminal air in left-sided acute colonic diverticulitis. Surg Infect (Larchmt) 2018;19:362-368.

112. You K, Bendl R, Taut C, Sullivan R, Gachabayov M, Bergamaschi R; Study Group on Diverticulitis. Randomized clinical trial of elective resection versus observation in diverticulitis with extraluminal air or abscess initially managed conservatively. $\mathrm{Br}$ J Surg 2018;105:971-979.

113. Cuomo R, Barbara G, Pace F, et al. Italian consensus conference for colonic diverticulosis and diverticular disease. United European Gastroenterol J 2014;2:413-442.

114. Lovell RM, Ford AC. Global prevalence of and risk factors for irritable bowel syndrome: a meta-analysis. Clin Gastroenterol Hepatol 2012;10:712-721.

115. Tănase I, Păun S, Stoica B, Negoi I, Gaspar B, Beuran M. Epidemiology of diverticular disease-systematic review of the literature. Chirurgia (Bucur) 2015;110:9-14.

116. Lacy BE, Mearin F, Chang L, et al. Bowel disorders. Gastroenterology 2016;150:1393-1407.e5.

117. Alamo RZ, Quigley EMM. Irritable bowel syndrome and colonic diverticular disease: overlapping symptoms and overlapping therapeutic approaches. Curr Opin Gastroenterol 2019;35:27-33.
118. Annibale B, Lahner E, Maconi G, et al. Clinical features of symptomatic uncomplicated diverticular disease: a multicenter Italian survey. Int J Colorectal Dis 2012;27:1151-1159.

119. Carabotti M, Cuomo R, Barbara G, et al. Demographic and clinical features distinguish subgroups of diverticular disease patients: Results from an Italian nationwide registry. United European Gastroenterol J 2018;6:926-934.

120. Cuomo R, Barbara G, Andreozzi P, et al. Symptom patterns can distinguish diverticular disease from irritable bowel syndrome. Eur J Clin Invest 2013;43:1147-1155.

121. Tursi A, Elisei W, Picchio M, Giorgetti GM, Brandimarte G. Moderate to severe and prolonged left lower-abdominal pain is the best symptom characterizing symptomatic uncomplicated diverticular disease of the colon: a comparison with fecal calprotectin in clinical setting. J Clin Gastroenterol 2015;49:218-221.

122. Lee SH, Kim CR, Kim KN. Changes in fecal calprotectin after rifaximin treatment in patients with nonconstipated irritable bowel syndrome. Am J Med Sci 2019;357:23-28.

123. Hong W, Dong L, Zippi M, et al. Colonic diverticulosis is not a risk factor for colonic adenoma. Ther Clin Risk Manag 2018; 14:531-537.

124. Morini S, Zullo A, Hassan C, Tomao S, Campo SM. Diverticulosis and colorectal cancer: between lights and shadows. J Clin Gastroenterol 2008;42:763-770.

125. Meyer J, Orci LA, Combescure C, et al. Risk of colorectal cancer in patients with acute diverticulitis: a systematic review and meta-analysis of observational studies. Clin Gastroenterol Hepatol 2019;17:1448-1456.e17.

126. Ierardi E, Hassan C, Zullo A, et al. Segmental colitis associated with diverticula: a rare clinical entity and a new challenge for the gastroenterologist. Dig Liver Dis 2009;41:794-797.

127. Imperiali G, Terpin MM, Meucci G, Ferrara A, Minoli G. Segmental colitis associated with diverticula: a 7-year follow-up study. Endoscopy 2006;38:610-612.

128. Ierardi E, Meucci G, Hassan C, et al. Tumour necrosis factor alpha in segmental colitis associated with diverticula. Dig Dis Sci 2008;53:1865-1868.

129. Kucejko RJ, Poggio JL. Considerations and changes in the evaluation, management, and outcomes in the management of diverticular disease: the diagnosis, pathology, and treatment of diverticular colitis. Clin Colon Rectal Surg 2018;31:221-225.

130. Ghorai S, Ulbright TM, Rex DK. Endoscopic findings of diverticular inflammation in colonoscopy patients without clinical acute diverticulitis: prevalence and endoscopic spectrum. Am J Gastroenterol 2003;98:802-806.

131. Scarpignato C, Barbara G, Lanas A, Strate LL. Management of colonic diverticular disease in the third millennium: Highlights from a symposium held during the United European Gastroenterology Week 2017. Therap Adv Gastroenterol 2018;11:1756284818771305.

132. Floch MH. A hypothesis: is diverticulitis a type of inflammatory bowel disease? J Clin Gastroenterol 2006;40 Suppl 3:S121-S125.

133. Horgan AF, McConnell EJ, Wolff BG, The S, Paterson C. Atypical diverticular disease: surgical results. Dis Colon Rectum 2001;44:1315-1318.

134. Peppercorn MA. The overlap of inflammatory bowel disease and diverticular disease. J Clin Gastroenterol 2004;38:S8-S10.

135. Schieffer KM, Kline BP, Yochum GS, Koltun WA. Pathophysiology of diverticular disease. Expert Rev Gastroenterol Hepatol 2018;12:683-692. 